Illinois State University

ISU ReD: Research and eData

Theses and Dissertations

6-26-2021

\title{
The Development of a Measure of Parent and Teacher Perceptions of the Importance of Social-Emotional Learning in the Schools
}

Heather M. Calkins

Illinois State University, hcalkins618@gmail.com

Follow this and additional works at: https://ir.library.illinoisstate.edu/etd

\section{Recommended Citation}

Calkins, Heather M., "The Development of a Measure of Parent and Teacher Perceptions of the Importance of Social-Emotional Learning in the Schools" (2021). Theses and Dissertations. 1430.

https://ir.library.illinoisstate.edu/etd/1430

This Dissertation is brought to you for free and open access by ISU ReD: Research and eData. It has been accepted for inclusion in Theses and Dissertations by an authorized administrator of ISU ReD: Research and eData. For more information, please contact ISUReD@ilstu.edu. 


\section{THE DEVELOPMENT OF A MEASURE OF PARENT AND TEACHER PERCEPTIONS OF THE IMPORTANCE OF SOCIAL-EMOTIONAL LEARNING IN THE SCHOOLS}

\section{HEATHER MAE CALKINS}

68 Pages

This dissertation presents a project that included two main objectives: 1) creating and validating a scale of teacher and parent perceptions of the importance of social-emotional learning (SEL) in the schools; and 2) examining differences among perceptions of SEL based on a variety of factors. Exploratory factor analyses indicate that all 50 original items related to the importance of including SEL in the schools loaded onto a single factor, SEL attitudes. Additional analyses indicate that this scale was highly reliable. Two additional subscales, academic priority and SEL effectiveness were also highly reliable and significantly correlated to SEL attitudes. The second component of this dissertation examined parent and teacher perceptions of SEL. Results indicate that parents perceive SEL as more effective compared to teachers. General education teachers with children with disabilities in their classrooms rated SEL effectiveness lower compared to general education teachers without children with disabilities in their classrooms and special education teachers. Teachers also rated academic priority significantly differently based upon the grade level that they teach. Future research should further validate the measure created as well as further investigate differences between parent and teacher perceptions of SEL.

KEYWORDS: Social-emotional learning; SEL; parent perceptions; teacher perceptions; instrument construction 


\title{
THE DEVELOPMENT OF A MEASURE OF PARENT AND TEACHER PERCEPTIONS OF
} THE IMPORTANCE OF SOCIAL-EMOTIONAL LEARNING IN THE SCHOOLS

\author{
HEATHER MAE CALKINS
}

\begin{abstract}
A Dissertation Submitted in Partial Fulfillment of the Requirements for the Degree of DOCTOR OF PHILOSOPHY Department of Psychology ILLINOIS STATE UNIVERSITY
\end{abstract}


(C) 2021 Heather Mae Calkins 
THE DEVELOPMENT OF A MEASURE OF PARENT AND TEACHER PERCEPTIONS OF THE IMPORTANCE OF SOCIAL-EMOTIONAL LEARNING IN THE SCHOOLS

HEATHER MAE CALKINS

COMMITTEE MEMBERS:

Gregory S. Braswell, Chair

Jeffrey Kahn

Adena B. Meyers

Amanda Quesenberry 


\section{ACKNOWLEDGMENTS}

I would like to thank my committee chair, Dr. Gregory Braswell, for supporting my ideas and helping me create a unique project. I would also like to thank committee members Dr. Adena B. Meyers, Dr. Jeffrey Kahn, and Dr. Amanda Quesenberry for providing a variety of ideas and resources throughout the process of finalizing my ideas for this project. I appreciate your

flexibility and understanding as my research project was adapted due to the COVID-19 pandemic.

I would also like to thank my cohort members who provided me with endless support and laughter throughout the entirety of my graduate school career. Without each of you, I surely would not be the individual and professional I am today. Five out of five!

H. M. C. 


\section{CONTENTS}

$\begin{array}{lr} & \text { Page } \\ \text { ACKNOWLEDGMENTS } & \text { i } \\ \text { CONTENTS } & \text { ii }\end{array}$

CHAPTER I: OVERVIEW OF THE STUDY 1

CHAPTER II: REVIEW OF THE LITERATURE 3

Social-Emotional Competence 3

$\begin{array}{ll}\text { Social-Emotional Learning } & 6\end{array}$

Ecological Systems Theory $\quad 8$

Parent and Teacher Beliefs about SEL in the Schools 11

SEL Attitude Scales $\quad 15$

$\begin{array}{ll}\text { The Current Study } & 19\end{array}$

CHAPTER III: METHODS 22

$\begin{array}{ll}\text { Participants } & 22\end{array}$

$\begin{array}{ll}\text { Measures } & 24\end{array}$

$\begin{array}{ll}\text { Procedure } & 29\end{array}$

CHAPTER IV: RESULTS $\quad 30$

CHAPTER V: DISCUSSION 35

$\begin{array}{ll}\text { REFERENCES } & 42\end{array}$

APPENDIX A: INITIAL SURVEY

APPENDIX B: FINAL ITEMS ON SCALES AFTER FACTOR ANALYSIS 60

APPENDIX C: TABLES AND FIGURES 


\section{CHAPTER I: OVERVIEW OF THE STUDY}

Social and emotional competence envelop the skills of recognizing and understanding emotions, managing one's emotions and behaviors, developing empathy for others, and utilizing effective problem-solving skills (CASEL, 2019). Research indicates that social and emotional competence contribute to a variety of positive outcomes for youth. High levels of social and emotional competence have been linked to increases in friendship-making skills, social inclusion, and academic competence (Crawford \& Manassis, 2011; Stepp et al., 2011). Simultaneously, social and emotional competence are related to decreases in anxiety, behavioral problems, and peer rejection (Henricsson \& Rydell, 2006; Matthews et al., 2016; Rydell et al., 2007).

Social-emotional learning is the process by which individuals become socially and emotionally competent. Social-emotional learning can be an implicit or explicit process and can include direct instruction, modeling, and prompting within the schools (Guralnick, 2010). As social and emotional competence have positive impacts on youth's psychological development, several states have adopted social-emotional learning standards for the schools (CASEL, 2019). However, it remains unclear how important stakeholders in children's lives, such as parents and teachers, perceive the importance of social-emotional learning in the schools.

Research regarding social-emotional learning indicates that there may be a discrepancy between parent and teacher perceptions of social-emotional learning such that teachers have a more positive attitude toward incorporating it into the schools (Burleson, Nelson, \& Tollefson, 1980; Calkins, 2019). Other researchers have identified common themes contributing to teachers' hesitation surrounding the implementation of social-emotional learning in the schools, including a lack of time during the school day to implement social-emotional learning and the 
belief that parents should be primarily responsible for social-emotional learning (Buchanan et al., 2009; Zinsser et al., 2014). These negating attitudes are likely hindering the implementation of social-emotional learning as well as its positive impact on students. Researchers must gain a more accurate understanding of current perceptions of social-emotional learning in order to pinpoint ways in which support for social-emotional learning can be enhanced across stakeholders.

This dissertation serves as an extension of a thesis project examining parent and teacher perceptions of social-emotional learning in the schools. This study adds to the literature in two primary ways. First, a measure of parent and teacher perceptions of social-emotional learning in the schools was created and validated. Second, parent and teacher perceptions of socialemotional learning in the schools were assessed. The results of this study will help future researchers as well as school administrators measure attitudes toward social-emotional learning. Additionally, the results of this study provide insight into parent and teacher perceptions of social-emotional learning in the schools. 


\section{CHAPTER II: REVIEW OF THE LITERATURE}

Relevant literature was found by entering key terms into the PsycInfo database. Key words and terms used included social-emotional learning, SEL, social-emotional competence, and parent and/or teacher perceptions of social-emotional learning. Research related to the constructs of social-emotional competence is described first. Then, social-emotional learning is introduced and defined. The theoretical underpinning for the study is introduced. The literature review concludes with a thorough analysis of current research on parent and teacher attitudes toward SEL as well as the assessments that exist to measure these attitudes.

\section{Social-Emotional Competence}

As individuals develop, they engage in reciprocal interactions with their environments that shape how they understand and respond to novel situations. An accumulation of experiences leads to the development of a specific set of skills that an individual may use when interacting with the environment. Competent, or effective, responses to environmental stimuli can be split into two domains: social competence and emotional competence.

Socially competent responses include perspective taking, effective problem-solving, and social skills (Cavell, 1990; Rose-Krasnor, 1997; Sarason, 1981). Social skills can be defined broadly as overt, learned behaviors which are performed by an individual to complete a social task (Sheridan, Hungelmann, \& Maughan, 1999). Covert socially oriented behaviors, such as perspective taking and problem-solving, aid an individual in enacting a behavioral response that appropriately fits the context and will lead to social success (Dodge, 1986).

Scholars engage in an ongoing dispute regarding how to best study social competence. While some scholars conceptualize social competence as a behavioral marker consisting of social adjustment and performance (Cavell, 1990), other scholars rely on the outcomes of the behaviors 
to signify social competence, including friendship quality and peer group acceptance (Hinde, 1987). When combined, these seemingly disparate conceptualizations yield the following definition: social competence encompasses socially oriented behaviors that are appropriately applied to social situations and that lead to desirable outcomes (CASEL, 2019).

Social competence is supported by the related construct of emotional competence. Emotionally competent responses involve skills that allow an individual to recognize and understand the emotions of the self and others, express and regulate one's own emotions, demonstrate empathy, and enhance one's own self-efficacy in dealing with emotion-arousing situations (Matthews et al., 2016; Saarni, 1999). Social and emotional competence are positively correlated such that high levels of emotional competence are related to higher levels of social competence (Hubbard \& Coie, 1994). Researchers posit that emotionally charged situations are typically social in nature; therefore, the ability to regulate one's emotions and understand the emotions of others aids an individual in engaging in positive social interactions (Blair et al., 2015; Saarni, 1999). However, other researchers emphasize that some individuals experience deficits in social competence that cannot be explained by difficulties in emotional competence. Berkovits and Baker (2014) concluded that emotional competence did not predict changes in social competence above and beyond measures of current social competence levels for youth with developmental delays. These results indicate that social and emotional competence are separate constructs that represent distinct skill sets. Support for the development of competence in both social and emotional domains should occur in tandem in order to maximize potential benefits.

Social and emotional competence are associated with a variety of positive outcomes for youth. Competence in both domains increases an individual's ability to establish and maintain 
friendships (Crawford \& Manassis, 2011; Garner \& Estep, 2001) and decreases the likelihood of peer rejection (Henricsson \& Rydell, 2006). In addition, social support is predictive of overall psychological well-being (Ciarrochi et al., 2017). The results of these studies indicate that the quality of a social relationship is the result of exhibited social and emotional skills, and positive social relationships can serve as protective factors against mental illness. In fact, researchers have investigated the link between social and emotional competence and various negative psychological outcomes. They have discovered negative associations between competence and behavioral problems (Rydell et al., 2007), anxiety (Matthews et al., 2016), and substance abuse (Jones, Greenburg, \& Crowley, 2015).

In addition to psychological outcomes, social and emotional competence have been linked to increases in academic performance. Specifically, emotional knowledge and social skills have been linked to increases in educational attainment (Carroll et al., 2001; Stepp et al., 2011). Researchers have speculated that the connection between social and emotional competence and increased academic performance may be mediated by positive mental health (Panayiotou et al., 2019). Therefore, supporting the social and emotional development of students can have a positive impact on students' mental health and, in turn, their academic performance.

There are several factors that may influence the development of social competence, including the presence of a disability in childhood. For example, children with developmental delays face difficulties in the development of social competence, as they may struggle to properly encode social situations, regulate their own emotions during peer interactions, understand social rules, and have deficits in prosocial behaviors. These specific difficulties often translate into difficulties for the child regarding initiating and maintaining peer relationships (Guralnick, 2010; Pierce-Jordan \& Lifter, 2005). In addition, children with learning disabilities 
face difficulties with social competence when compared to their typically-developing peers (Bender \& Wall, 1994). These difficulties manifest themselves in a variety of ways including lower teacher-rated social competence (Nowicki, 2003), increased likelihood of designation to the rejected group via sociometric assessments (Sater \& French, 1989), and self-reported difficulties with friendship-making skills and poor friendship quality (Normand et al., 2011; Zeedyk et al., 2016). Other disabilities have also been linked to deficits in social competence, including ADHD (Thorell \& Rydell, 2008), autism spectrum disorder (American Psychiatric Association, 2013), specific language impairment (McCabe \& Meller, 2004), physical impairments (Yagmurlu \& Yavuz, 2015), and psychiatric disorders (Matthews et al., 2016).

The presence of a disability may also affect the development of emotional competence. Children with emotional disturbances and ADHD have difficulties regulating their emotions and behaviors in response to emotionally arousing stimuli (Saarni, 1999; Semrud-Clikeman \& Schafer, 2000). Several other disabilities have been linked to difficulties with emotional competence, including developmental delays (Berkovits \& Baker, 2014), intellectual disabilities (Pochon \& Declerq, 2014), learning disabilities (Elias, 2004), and autism spectrum disorder (Begeer et al., 2008). This study assessed whether these documented difficulties in the development of social and emotional competence for children with disabilities translated to differential ratings of the importance of SEL by parents or teachers.

\section{Social-Emotional Learning}

Students' social and emotional competence develop as a result of social-emotional learning (SEL). SEL can be defined as the process by which individuals acquire knowledge and skills in a wide variety of social, emotional, and behavioral domains. Specifically, individuals learn to do the following: 1) identify and understand emotions of the self and others; 2) manage 
their emotions and behaviors; 3) develop social awareness and empathy; 4) use social problemsolving strategies; and 5) establish and maintain positive relationships with others (CASEL, 2019; Schonfeld et al., 2015).

SEL can be conceptualized as an ongoing process consisting of an individual's experience of and responses to emotionally-charged social situations. However, SEL can be a deliberate process determined by explicit instruction and coaching related to any of the five major domains listed above. As of 2019, fourteen states in the United States have provided guidelines regarding the inclusion of SEL learning standards for kindergarten through twelfth grade enrolled in public schools (CASEL, 2019). These guidelines do not outline how SEL should be incorporated into the schools or who is in charge of implementation, but rather outline a set of specific social-emotional goals for students across grade levels. A few strategies that have been found to support SEL include fostering inclusive classrooms in which students with disabilities are placed in classrooms alongside their typically-developing peers, prompting the regular use of skills in the classroom, utilizing formal SEL curricula, and changing school structure to enhance school climate (Buckley et al., 2003; Guralnick, 2010; Kwon et al., 2011; Meyers \& Hickey, 2014).

The implementation of SEL in the schools is related to a variety of positive outcomes for youth. SEL curricula increase students' abilities to manage their emotions and impulses, engage in positive peer interactions, and attain an overall sense of social-emotional well-being (Ashdown \& Bernard, 2012; Zhai et al., 2015). In addition, explicit SEL instruction in the schools leads to increased academic performance by up to $11 \%$ for children between kindergarten and twelfth grade (Durlak et al., 2011). These data indicate that SEL enhances 
social and emotional competence as well as academic performance. Explicit SEL instruction and guidance, therefore, supports overall child development.

SEL may be of particular benefit to children with disabilities. Research indicates that individuals with a variety of disabilities have specific social and emotional skill deficits (American Psychiatric Association, 2013; Berkovits \& Baker, 2014; Matthews et al., 2016; McCabe \& Meller, 2004; Pochon \& Declerq, 2014; Thorell \& Rydell, 2008; Yagmurlu \& Yavuz, 2015). Espelage, Rose, and Polanin (2016) implemented SEL with students with disabilities across the midwestern United States. They concluded that students with disabilities had increases in prosocial behaviors, including willingness to intervene in bullying, and increases in academic performance. Additionally, results of a longitudinal study conducted by Kam, Greenberg, and Kusché (2004) indicate that children with disabilities in first through third grade who received instruction with the Promoting Alternative THinking Strategies (PATHS) curriculum decreased both internalizing and externalizing behaviors compared to the control group. Additionally, these results were maintained 2 years after the intervention. These results indicate that SEL can have positive impacts on children with disabilities both related to skill development and mental health. This study explored whether parents and teachers believe SEL is differentially important for students with disabilities compared to typically-developing students.

\section{Ecological Systems Theory}

SEL occurs across many environments for youth. Youth are embedded within several environments including their homes, their schools, their peer groups, and the larger society. As youth navigate these environments, they gain experiences and knowledge that support the development of social and emotional competence. 
The ecological systems theory states that individuals are situated within various contexts that can directly or indirectly influence the individual's attitudes, beliefs, and behaviors (Bronfenbrenner, 1977). Microsystems are environments with which an individual has direct contact, such as the home and school environments. These microsystems interact with one another, creating the mesosystem. In addition, the context of the larger social system impacts an individual more indirectly. Legislation, history, and culture comprise this social system called the macrosystem (Bronfenbrenner, 1977).

Each layer of an individual's context uniquely impacts the individual, and interactions between contexts can alter that impact. At the mesosystem level, the home and school environments interact with regard to the expectations held for a child. Specifically, parents and teachers may have similar approaches to supporting social, emotional, and behavioral development. Research indicates that such congruence across contexts is conducive to positive, long-term social and emotional outcomes for youth (Sheridan et al., 2004).

Congruence between the home and school environments is referred to as home-school collaboration. During home-school collaboration, adult stakeholders from both the home and school environment share in the decision-making process regarding a child. These stakeholders enter into a collaborative decision-making process regarding academic, social, emotional, or behavioral goals for a child. All individuals involved in the decision-making are also committed to supporting the child in attaining the goals identified (Cowan et al., 2004).

Home-school collaboration has been linked to myriad positive outcomes, including positive behaviors and academic achievement (Sheridan et al., 2004). Collaborative efforts may be particularly beneficial for students with disabilities and younger children. Specifically, research indicates that collaboration focused on improving parental responsiveness and positive 
interaction patterns are related to children's developmental improvements including language skills and social-emotional well-being (Mahoney \& Wiggers, 2007; Wellner, 2012). In addition, researchers suggest that children with social, emotional, and behavioral concerns may maximally benefit from interventions that include both teachers and parents because children's social, emotional, and behavioral skills develop in numerous settings, including the home and school (Guralnick, 2010).

The present study examined the mesosystem-level interaction between the home and school environments specifically in relation to beliefs about SEL. The beliefs of these key stakeholders in a child's life may interact in such a way that could enhance or hinder a child's social, emotional, and behavioral development. For instance, a lack of congruence between parents and teachers regarding the importance of SEL in the schools may result in children receiving different social, emotional, and behavioral supports at home and at school. These differing practices may hinder child development. In addition, a lack of congruence between these contexts regarding beliefs about SEL may represent an area of concern for school systems as they strive to enhance home-school collaboration. Understanding parent and teacher beliefs about SEL and how they may differ is crucial in identifying ways in which schools can increase support for SEL.

Furthermore, as indicated above, 14 states in the United States have created guidelines for the inclusion of SEL goals in public schools for youth in kindergarten through twelfth grade (CASEL, 2019). Positive attitudes toward SEL in these states may differ from states for which these SEL guidelines are not present, representing a macrosystem-level influence. This research analyzed whether the presence of SEL guidelines in a state resulted in differing beliefs regarding the importance of SEL in the schools. 


\section{Parent and Teacher Beliefs about SEL in the Schools}

Parent and teacher perceptions are an important area of study, as attitudes toward SEL influence the nature of SEL supports provided to youth. Teacher perceptions are particularly important, as attitudes toward SEL, perceptions of the feasibility of implementing SEL practices, and motivation to engage in SEL practices can influence the implementation of SEL in the classroom (Schonert-Reichl, 2017). In terms of motivation to implement SEL, Greenberg and colleagues (2005) posit that teachers are more likely to implement only those specific components of a program that they perceive as important for their students' development. Therefore, understanding teacher perceptions of different components of SEL and its impact on students is crucial to supporting the implementation of SEL in the schools.

Research conducted by Buchanan and colleagues (2009) indicates that $98.9 \%$ of teachers surveyed perceive SEL to be important for success in school and life in general. In addition, 96.2\% of respondents agreed that SEL has a positive impact on academic functioning. However, other researchers have reported lower percentages which indicate a lower degree of support for SEL. Specifically, Bridgeland, Bruce, and Hariharan (2013) conducted a more comprehensive, national survey of teachers and found that only $76 \%$ of teachers viewed SEL as very important to include in schools. In addition, only $36 \%$ of teachers surveyed responded that SEL has a positive impact on academic performance, with $18 \%$ responding that they think SEL has no effect on academic performance.

Based on current research, the extent to which teachers support the inclusion of SEL in the schools is unclear. If teachers do not believe SEL has positive benefits, they may be less motivated to engage in SEL practices within their classrooms. Indeed, only $68.9 \%$ of teachers surveyed in one study believed that SEL should be taught in the classrooms (Buchanan et al., 
2009). Many teachers reported that it was not feasible to implement SEL due to time and resource constraints. Furthermore, teachers report the belief that parents should be primarily responsible for SEL and that SEL does not belong in the schools (Zinsser et al., 2014). These attitudes likely undermine the implementation of SEL, as teachers may not acknowledge the utility of SEL or how it fits into the school.

One factor that influences teacher perceptions of the importance of SEL in the schools is grade level. Bridgeland and associates (2013) conducted a national study that asked teachers to rate the importance of SEL for different age groups. The results indicated that teachers believe integrating SEL into the schools is less imperative as youth age. Specifically, 77\% of teachers surveyed agreed that SEL is an important component of schooling for children in preschool and elementary grades. However, only $69 \%$ of teachers believed SEL was important to include in middle school, and 56\% believed SEL was important to include in high school. The results also indicated that of high school teachers surveyed, only $42 \%$ believe SEL belongs in the schools at the high school level. Overall, teachers seem to be less concerned with implementing SEL at higher grade levels, particularly teachers who are interacting with students in these grades. These data represent a concern in light of SEL mandates and guidelines and require further study. Another factor that influences teacher perceptions of SEL is whether teachers have experience with students with disabilities. Studies have shown that general education teachers in inclusive classrooms are more likely to appreciate the importance of social goals for children with disabilities compared to special education teachers in self-contained classrooms (Kwon et al., 2011). These data indicate that teachers of inclusive classrooms may be more attuned to individual students' social and emotional competence due to their exposure to a wider range of 
competence levels. This study investigated whether perceptions of SEL differ based on classroom composition.

Past research has primarily focused on teacher perceptions of SEL while largely ignoring another major microsystem at play in children's lives: the family. Parent perceptions of SEL are an important area of study, as home-school collaboration is related to positive outcomes for youth (Sheridan et al., 2004). If parents are supportive of SEL, similarly to teachers in the schools, parents and teachers can engage in similar behaviors to support the development of an individual child's social and emotional competence.

Parent perceptions of SEL may be less positive compared to those of teachers. One study conducted in 1980 asked parents and teachers to rate 29 items related to three broad ideas related to SEL: 1) the appropriateness of affective, or emotional, education in elementary schools; 2) the appropriate time to allot to academic or affective education and whether one should be given more of a time priority; and 3) the value of specific activities related to affective education (Burleson et al. 1980). This study revealed a significant difference between parent and teacher perceptions of SEL such that teachers were more supportive of affective education overall compared to parents. However, this study was conducted in 1980; a more updated look at the differences between parent and teacher perceptions was needed.

As part of the author's previous research, the study by Burleson, Nelson, and Tollefson (1980) was replicated (Calkins, 2019). Parents and teachers of youth in public schools in Illinois completed identical questionnaires that were created by the researcher to assess their perceptions of the importance of SEL in the schools. Participants first completed Likert-scale ratings of their perception of how appropriate it is to integrate SEL into the schools. Teachers rated SEL as more important compared to parents, thereby replicating the major finding of the study conducted in 
1980. Qualitative responses regarding their responses to the Likert-scale items revealed that $43.2 \%$ of teachers and $25.8 \%$ of parents surveyed believed SEL had a positive impact on academic performance. Thematic analysis of qualitative responses revealed prevalent themes including the need to support the whole child in the school (18.9\% of teachers, $15.1 \%$ of parents) and supporting students as future members of society (18.9\% of teachers, $21.5 \%$ of parents). In addition, specific SEL goals were included as items of a rank-order paradigm to determine the priorities that parents and teachers have for SEL in comparison to academic goals. There was no difference between how parents and teachers prioritized these items according to an independent samples $t$-test. However, thematic analyses of qualitative responses indicated that $45.2 \%$ of teachers placed an emphasis on SEL goals whereas only $19.5 \%$ of parents prioritized SEL goals. Conversely, only $6.5 \%$ of teachers placed an emphasis on academic goals compared to $26.8 \%$ of parents. These results indicate that teachers view SEL as more important in the school compared to parents and are more likely to understand the impact SEL has on academic success.

Calkins (2019) also attempted to determine whether participants rated the importance of SEL differently based on experience with children with disabilities. No significant results were found for parents or teachers. In addition, particular concerns about SEL implementation emerged via further qualitative analyses. Consistent with past research, participants opined that parents should primarily be responsible for SEL ( $24.3 \%$ of teachers, $16.1 \%$ of parents) and schools have limited time and resources to implement SEL (8.1\% of teachers, $5.4 \%$ of parents).

Although helpful in replicating a prior study, the study conducted by Calkins (2019) was limited in scope due to its geographical specificity and small sample size. The current study attempted to provide a national view of parent and teacher perceptions of the importance of different SEL goals. Additionally, this study re-examined the potential differences in perceptions 
between parents and teachers with and without experience with children with disabilities.

Researchers also attempted to create and validate a measure of parent and teacher perceptions of SEL that school personnel may find useful in the process of SEL implementation.

Additional research related to parent perceptions of SEL indicate that parents of children with disabilities may view SEL more positively compared to parents of typically-developing children (Spann et al., 2003). Specifically, parents of children with autism spectrum disorder or pervasive developmental disorder were asked about their goals for their children. Fifty-one percent of the parents who participated in the study indicated that successfully interacting with peers and making friends were among their top priorities for their children. These results indicate that these parents may prioritize social skill development for their children; however, all respondents were parents of children with autism spectrum disorder or pervasive developmental disorders. Because these disorders are characterized by impairments in social reciprocity, this study does not provide a representative view of parent priorities for children with disabilities. In fact, Lindsay and colleagues (2016) concluded that parents of children with autism spectrum disorder were more concerned with their child's social and emotional development compared to parents of children with language impairments. Therefore, a more comprehensive look at parents of children with a variety of disabilities is warranted to determine whether these parents tend to prioritize SEL more highly compared to parents of typically-developing children. Additionally, it is unclear how parents of children with disabilities will respond to items when considering what skills all children should learn within the schools.

\section{SEL Attitude Scales}

Bridgeland and colleagues (2013) called for schools to conduct assessments of readiness for SEL. Attitudes toward SEL are one of the components that contribute to readiness to 
implement SEL. Few studies have created scales that assess perceptions of SEL in the schools. The majority of studies contained in this literature review analyzed responses to single items rather than a validated measure of SEL attitudes. There is a gap in the current literature such that no such scale exists and is widely available for use.

Burleson, Nelson, and Tollefson (1980) created a 29-item measure to assess parent and teacher attitudes toward affective education. The questionnaire specifically assessed how appropriate participants thought the inclusion of affective education was at the elementary school level, whether affective or academic education should be granted more time than the other, and how valuable specific affective activities were. These items yielded a single score representing an overall attitude toward affective education for each participant. This questionnaire had a Hoyt reliability of .84 and coefficient stability of .96 . In addition, the researchers assessed content validity by having third party raters indicate the clarity and perceived relation to the topic of affective education for each item. All but one item was rated as "good" or "excellent". This study made an important contribution by developing a scale to assess these attitudes. However, our conceptualization of SEL has undergone significant transformations both in its scope and its specificity. Specifically, core domains, short-term and long-term goals, and guidelines have been released in recent years to guide schools through successful implementation of a comprehensive SEL program (see CASEL, 2019). Therefore, it is important to align an SEL attitudes scale with current research related to the core components of SEL. In addition, this scale was only intended for use with elementary schools; research indicates that SEL is important to include at all grades (CASEL, 2019). Additionally, teachers of higher grades may have less-positive attitudes toward SEL (Bridgeland et al., 2013); therefore, including teachers at all grades is imperative. 
Schultz and colleagues (2010) also created and validated a measure of teacher attitudes toward SEL called the Teacher Attitudes about Social and Emotional Learning (TASEL). A factor analysis revealed that their measure assessed teachers' perception of administrative support for SEL as well as teacher readiness to implement SEL along five domains: training related to SEL, perceived self-competence in implementing SEL practices, perceptions of the effectiveness of SEL, time constraints on implementing SEL, and the tendency to prioritize academics over SEL. Researchers retained items that had loadings of .40 or higher on one factor and ensured that each factor had at least 4 items. Factors had acceptable reliability with the exception of time constraints. In addition, factors generally were moderately correlated with one another. Finally, they assessed the predictive validity of their scale by regressing one item assessing the extent to which SEL is implemented in the school on each factor. All factors combined accounted for $40 \%$ of the variance. Three scales significantly contributed unique variance to the prediction model: administrative support, academic priority, and time constraints. This indicates that these three variables contribute significantly to predicting SEL implementation. Although the TASEL is touted as a measure of teacher perceptions of SEL, only two domains tap into teachers' true perceptions of SEL free from constraints: perceptions of the effectiveness of SEL and the tendency to prioritize academics over SEL. While the researchers of this dissertation study acknowledge the importance of constraints such as inadequate training and a lack of time to devote to SEL, these considerations should inform how individual schools address training needs and do not represent a clear picture of teacher perceptions of the importance of SEL in the schools.

The Collaborative for Academic, Social, and Emotional Learning (CASEL) created a survey, called the CASEL-AIR, to assess SEL implementation (n.d.). This survey has 6 item 
clusters that assess staff's perceptions of school-level theory of action to implementing SEL. The item clusters address the following areas: 1) the degree to which the school, in conjunction with other stakeholders, has developed a vision for including SEL; 2) the degree to which the school has evaluated its resources to implement SEL; 3) the degree to which the school supports professional development surrounding SEL topics; 4) the degree to which the school has implemented evidence-based SEL; 5) the degree to which the school has integrated SEL into academic instruction; and 6) the degree to which the school has emphasized continuous improvement of SEL initiatives. The survey's item clusters have adequate internal consistency (ranging from .7 to .93). This survey also includes three subscales that assess staff commitment to SEL implementation, actual implementation efforts, and district support for SEL. Internal consistency was not reported for these subscales. This survey provides another example of teacher-only attitude ratings. While it does assess for the degree to which parents are involved in the development of the school's vision for SEL, it does not allow for parents to directly provide ratings on their perceptions of SEL in the schools. More importantly, this survey focuses on theory of action for schoolwide SEL implementation; therefore, this survey is more beneficial for use when a school has already begun implementation of schoolwide SEL. The proposed survey in this project would be most helpful to schools who need to gauge parent and teacher buy-in to SEL prior to SEL implementation.

Brackett and colleagues (2012) also created and validated a measure of teacher beliefs about SEL. Exploratory factor analyses revealed three factors: 1) Comfort with implementing SEL; 2) Commitment to learning about SEL; and 3) Culture of the school and the extent to which it supports SEL. The reported Cronbach's alphas for each scale was above .74. Confirmatory factor analyses confirmed that the three-factor structure was the best-fit model. 
The final version of the measure has 12 items, with 4 items corresponding to each identified factor. The authors of this study made significant strides toward creating a valid measure of teachers' beliefs toward SEL. However, these factors appear to align with intentions to implement SEL, both at the individual and school levels, as well as the resources available to implement SEL rather than attitudes toward SEL in the schools. Specifically, the Comfort factor relates more to resources and training available to support the teachers' implementation of SEL in their classrooms. Additionally, the Culture piece is related to the administrator's support of and beliefs toward SEL rather than the teachers' beliefs. The Commitment factor also pulls on the resources available to implement SEL, as the availability of training, time, and funding impacts teacher intentions to implement SEL in conjunction with attitudes toward SEL.

The current study attempted to create and validate a measure of both teacher and parent perceptions of SEL. The items on this measure were aligned with CASEL's 5 Core Domains of SEL: self-awareness, self-management, social awareness, relationship skills, and responsible decision-making (CASEL, 2019). In addition, convergent validity was analyzed using components of the TASEL, created by Schultz and colleagues (2010), assessing the perceptions of the effectiveness of SEL and academic priority.

\section{The Current Study}

The purpose of this study was to validate a measure of perceptions of SEL in the schools aligned with CASEL's (2019) definition of SEL. Exploratory factor analyses were conducted on the three subscales created. Analyses assessing the internal reliability of each subscale and correlations among the subscales were also conducted. Additionally, the following research questions were addressed: 
1) Do parents and teachers rate the importance of SEL (SEL attitudes) in the schools differently?

Based on past research, it was hypothesized that teachers would rate the importance of SEL more highly compared to parents (Burleson et al., 1980; Calkins, 2019).

2) Do parents and teachers differ in their perceptions of balancing SEL and academic subjects (academic priority) in the schools?

This analysis was exploratory in nature. There was no hypothesized difference.

3) Do parents and teachers rate the perceived effectiveness of SEL (SEL effectiveness) in the schools differently?

This analysis was exploratory in nature. There was no hypothesized difference.

4) Do parent and teacher ratings of the importance of SEL differ based on experience with students with disabilities?

Past research has indicated that parents (Lindsay et al., 2016; Spann et al., 2003) and teachers (Kwon et al., 2011) may prioritize social and emotional supports for children with disabilities. Therefore, it was hypothesized that parents and teachers with experience with students with disabilities would rate SEL more positively compared to parents and teachers without experience with students with disabilities.

5) Do teacher perceptions of SEL differ based upon the grade level they teach? 
Based on past research conducted by Bridgeland and associates (2013), it was hypothesized that teachers of elementary-aged students would have more positive attitudes toward SEL compared to teachers of older students (e.g. middle and high school).

6) Are parent and teacher perceptions of SEL different based upon whether their state of residence provides guidelines for the inclusion of SEL?

Fourteen states now have guidelines related to social-emotional goals in the curriculum for kindergarten through twelfth grade (CASEL, 2019). However, it is unclear how parents and teachers in these states view the importance of including SEL in the schools. It was hypothesized that parents and teachers in states which have SEL guidelines would view SEL more positively compared to parents and teachers in other states due to increased exposure to SEL and its benefits.

7) Do parent and teacher perceptions of SEL differ based on location of residence? (e.g. rural, urban, or suburban region; geographical region of the United States) These analyses were exploratory in nature. There were no hypothesized differences. 


\section{CHAPTER III: METHODS}

\section{Participants}

The researchers intended to recruit a representative sample of parents and teachers across the United States. Parents and teachers with students in kindergarten and above enrolled in public schools were recruited. Parents and teachers of children in preschool were excluded from the study for two main reasons. First, extensive research has been conducted with this population regarding the inclusion and importance of SEL (see Bierman \& Motamedi, 2015). Second, all 50 states have SEL mandates and/or guidelines for preschool (CASEL, 2019). Although these goals may differ between states, research indicates that individuals agree that SEL is important for children in preschool (Bridgeland et al., 2013). Furthermore, this research only included parents and teachers of children in public school settings, as other types of schools (e.g., charter schools, day treatment schools) vary considerably in terms of their curriculum, structure, and treatment of SEL. In addition, this study explored the impact of SEL guidelines on attitudes toward SEL for parents and teachers; public schools, but not private schools, must abide by these statewide guidelines.

Participants were recruited using snowball sampling via social media platforms. The link to the survey was distributed on social media and called for parents and teachers of children in public schools in the United States to complete the survey. In addition, random sampling of states, cities, and schools was utilized. The researcher used a random number generator in order to select 10 different states, 10 different cities within each state, and random schools within each city (5 elementary schools, 3 middle / junior high schools, and 3 high schools). An e-mail was then sent to representatives of each school (superintendent, principal, or school psychologist) explaining the dissertation project and providing the recruitment flyer and study link. Few 
representatives replied to either agree to participate or decline participation; therefore, it is largely unknown which randomly selected schools chose to participate.

Approximately 150 parents and 150 teachers were needed in order to carry out a factor analysis as part of the validation process (Mundfrom et al., 2005). However, due to the COVID19 pandemic, I had difficulties recruiting an adequate sample. Due to ongoing difficulties with recruitment, I added student teachers in their final year of schooling at a public university in Illinois as potential teacher participants. Student teachers were recruited via a mass e-mail. Recruitment was partly randomized via the e-mails to specific schools, but was non-randomized as the researchers also included snowball sampling and targeted student teachers at a specific university in Illinois.

The sample was comprised of 85 teachers, including student teachers, and 122 parents. Responses from individuals who were not current parents or teachers of students in kindergarten and above at the time of survey completion were excluded from analyses. With these responses excluded, the final sample consisted of 70 teachers and 122 parents.

The average age of the overall sample was 40 years $(S D=8.91)$. Ninety-one percent of the sample was White, $3 \%$ was Hispanic/Latino(a), 2\% was African American, $1 \%$ was Asian American, $1 \%$ was Other, and $2 \%$ did not respond. Eighty-six percent of the sample was female, and $13 \%$ was male. Regarding location of residence, $43.5 \%$ lived in a suburban region, $35.1 \%$ lived in a rural region, and $21.5 \%$ lived in an urban region. Approximately $66 \%$ of the total sample resided in Illinois, and the remaining participants were from various other states (see Appendix C, Table 1). Additionally, approximately $81 \%$ of the total sample resided in the geographic Midwest (see Appendix C, Table 2). The number of participants from Illinois is not surprising, as the primary method for data collection was snowball sampling; many of the 
individuals connected to the researchers via social media lived in Illinois. Additionally, student teachers at a public Illinois university were also recruited for participation.

The average age of parents was 40 years $(S D=6.99)$, with a minimum of 24 years and a maximum of 62 years. The parent sample was 90.2\% White, 2.5\% Hispanic/Latino(a), 1.6\% African American, 0.8\% Asian American, 0.8\% Other, and 2.5\% No Response. The parent sample was $84.4 \%$ female and $14.8 \%$ male. Regarding location of residence, $46.7 \%$ of the parent sample lived in a suburban region, $28.7 \%$ lived in a rural region, and $23.8 \%$ lived in an urban region. Seventy-three percent of the parent sample resided in the Midwest, $10.7 \%$ lived in the West, $8.2 \%$ lived in the South, $4.1 \%$ lived in the Northeast, and $0.8 \%$ lived in the Pacific.

The average age of teachers was 40 years $(S D=11.45)$, with a minimum of 21 years and a maximum of 64 years. The teacher sample was 90\% White, $4.3 \%$ Hispanic/Latino(a), 1.4\% African American, 1.4\% Asian American, 1.4\% Other, and 1.4\% No Response. The teacher sample was $87.1 \%$ female and $11.4 \%$ male. Regarding location of residence, $45.7 \%$ of the teacher sample lived in a rural region, $37.1 \%$ lived in a suburban region, and $17.1 \%$ lived in an urban region. Almost 89\% of the sample lived in the Midwest, $7.1 \%$ lived in the West, $1.4 \%$ lived in the Northeast, and $1.4 \%$ of lived in the South. Of the teacher respondents, $32.9 \%$ were elementary teachers (defined as kindergarten through $5^{\text {th }}$ grade), $34.3 \%$ were middle school teachers (defined as $6^{\text {th }}$ through $8^{\text {th }}$ grade), $11.4 \%$ were high school teachers (defined as $9^{\text {th }}$ grade and above), $7.1 \%$ were "other" (e.g. $7^{\text {th }}$ through $12^{\text {th }}$, kindergarten through $8^{\text {th }}$ grade), and $14.3 \%$ did not respond.

\section{Measures}

One major goal of this dissertation project was to create and validate a scale regarding parent and teacher perceptions of the importance of including SEL in the schools. Clark and 
Watson (1995) outline several steps necessary in developing a valid and reliable scale. First, it is imperative to carefully define the constructs of interest using relevant research. Based on CASEL's (2019) conceptualization of SEL, I had five main constructs to define: self-awareness, self-management, social awareness, relationship skills, and responsible decision-making.

For the purpose of this study, I adhered to CASEL's (2019) definitions of these five constructs. Self-awareness is defined as the ability to understand one's thoughts and feelings as well as recognize how they impact one's own behavior. Self-awareness also includes understanding one's own strengths and abilities. Self-management refers to the ability to regulate one's own thoughts, feelings, and behaviors. It encompasses impulse control, stress management, and self-discipline. It also encompasses skills related to setting goals, motivating the self to achieve the goals, and organizing oneself in pursuit of the goals. Social awareness is defined as the ability to engage in perspective-taking, respectful behavior towards others, and empathymotivated behaviors. It also entails the ability to understand rules and norms related to behavior in a variety of settings. Relationship skills refers to the ability to establish and maintain positive relationships with others and encompasses appropriate communication, social engagement efforts, and teamwork. Finally, responsible decision-making encompasses skills related to making appropriate decisions about one's own behavior. The responsible decision-making process includes identifying the problem, analyzing the situation, generating possible solutions and choosing one, and evaluating the efficacy of one's decision.

Two other constructs that Schultz and colleagues (2010) included in their study are relevant to the current study. One construct measured the importance placed on academics in comparison to SEL within the schools. This construct was referred to as academic priority for the purpose of this study, and items entailed asking participants whether they believed that math 
and reading goals were more or less important than social-emotional goals. In addition, this study included the construct of SEL effectiveness which measured teacher and parent beliefs regarding the positive impacts SEL can have on students' social and emotional competence as well as their academic performance.

Once the constructs were adequately defined, a comprehensive item pool was created (Clark \& Watson, 1995). Ten items for each of the seven constructs were outlined for the measure (see Appendix A). Items were created based on CASEL's (2019) inclusion of specific skills for each of the five core SEL domains. For the two additional constructs (academic priority and SEL effectiveness), items were adapted from past research (Calkins, 2019; Schultz et al., 2010).

Next, a format was chosen related to the way in which participants responded to items on the measure. The current research project employed a Likert-scale response format, consistent with other attitude measures (Colton \& Covert, 2007). Parents and teachers were asked to indicate their level of agreement with each statement on a scale from 1 (strongly disagree) to 6 (strongly agree). Participants also provided demographic information such as their gender, age, race and ethnicity, whether they were a parent or a teacher, their state of residence, and whether they reside in a rural, urban, or suburban region. Teachers were also asked the grade that they teach. Both parents and teachers were asked about their experience with students with disabilities. For teachers, this indicated whether they currently have students with disabilities in their classroom and whether they were a general education or special education teacher. For parents, this indicated whether they have one or more children who have a disability. This information was used to identify the population with which the scale was validated. 
After the scales were administered to a relevant population of individuals, exploratory factor analyses were conducted to determine how the items loaded onto various factors. All factor analyses used principal axis factoring with a direct oblimin rotation. In addition, statistical procedures to determine internal consistency and reliability were conducted. Correlation analyses were also conducted to determine the correlations between the finalized subscales.

The initial exploratory factor analysis of the 50 items assessing attitudes toward SEL along CASEL's five domains, when five factors were extracted, revealed that $49.86 \%$ of the variance was explained by a single factor with an Eigenvalue of 24.93. The other four factors extracted had Eigenvalues between .96 and 2.47 and, when combined with the initial factor, explained $62.84 \%$ of the variance. A visual analysis of the Scree plot indicated that a one-factor model best explained the data (see Appendix C, Figure 1). All 50 items loaded onto this single factor above the initial 0.40 cutoff (See Appendix C, Table 3). A single factor, SEL attitudes, was extracted from the analysis and all 50 original items were retained. Responses to all 50 items were averaged together to create a new score for each participant, hereafter referred to as $S E L$ attitudes. Internal consistency indices were calculated to determine the internal consistency of the SEL attitudes scale. The Kaiser-Meyer-Olkin Measure of Sampling Adequacy (KMO) was .94. Cronbach's alpha was .98 for all 50 items, indicating excellent internal reliability.

Additionally, an exploratory factor analysis was conducted on the ten items assessing the perceptions of SEL effectiveness. One of the ten Likert-scale items expected to load onto this factor was reverse coded. When one factor was extracted, the exploratory factor analysis indicated that $51.48 \%$ of the variance was explained by one factor with an Eigenvalue of 5.58. A visual analysis of the Scree plot confirmed that a one-factor model best explained the data. One item loaded below the 0.40 cutoff and was thus excluded from further analyses (see Appendix C, 
Table 4). The KMO was .91. A single factor, SEL effectiveness, was extracted from the analysis, and nine of the ten original items were retained. Scores on these nine items were averaged together to create a new score for each participant, hereafter referred to as SEL effectiveness. Cronbach's alpha for the nine items was .91, indicating excellent internal validity.

An exploratory factor analysis was also conducted on the ten items assessing the perceptions of SEL's importance in relation to academics. Eight of the ten Likert-scale items expected to load onto this factor were reverse coded. When one factor was extracted, the exploratory factor analysis indicated that $43.63 \%$ of the variance was explained by one factor with an Eigenvalue of 4.87. A visual analysis of the Scree plot confirmed that a one-factor model best explained the data. All ten items loaded onto this single factor above the initial 0.40 cutoff (see Appendix C, Table 5). The KMO was .91. A single factor, academic priority, was extracted from the analysis, and all ten original items were retained. Responses to these ten items were averaged together to create a new score for each participant, hereafter referred to as academic priority. The Cronbach's alpha for the ten items was .87 , indicating good internal reliability.

A bivariate correlation analysis was conducted to determine the correlations between the scales. Scores on SEL attitudes were significantly correlated with both SEL effectiveness ( $r=$ $.68, p<.001)$ and academic priority $(r=.36, p<.001)$. Additionally, SEL effectiveness and academic priority were significantly correlated with one another, $r=.60, p<.001$.

Items from the TASEL were included to determine convergent validity of the subscales academic priority and SEL effectiveness (Schultz et al., 2010). The academic priority items from the TASEL originally reflected wording specific to the setting with which Schultz and colleagues (2010) worked. The original items referred to "director" and "education coordinators" and whether they give more importance to academics compared to SEL. For the purpose of the 
current study, the wording was changed to "principal" in order to provide a more universal parallel to an individual in power within the schools. The one item assessing Academic Priority on the TASEL was not significantly correlated with this study's subscale academic priority, $r=$ .-.07, $p=.33$. However, the four items on the TASEL assessing Program Effectiveness did significantly correlate with this study's subscale SEL effectiveness, $r=.76, p<.001$.

\section{Procedure}

A link to a Qualtrics survey was provided to potential participants. Informed consent was obtained from all participants. Once they provided consent to take part in the study, they completed the survey.

Due to ongoing difficulties with recruitment, incentives were added in the final two months of data collection which offered $\$ 10$ Visa/MasterCard gift cards to 20 randomly selected participants. After participants completed the survey, they were invited to follow a link on the final page of the survey to a separate Qualtrics survey that asked them to enter their e-mail into the drawing for the gift cards. Funding was provided by Illinois School Psychology Association following a grant application submission. 


\section{CHAPTER IV: RESULTS}

Hypothesis 1: An independent samples $t$-test was conducted to compare parent and teacher responses regarding their beliefs about the inclusion of SEL in the schools. Higher scores indicate more positive attitudes toward the inclusion of SEL in the schools. There was not a significant difference between how parents $(n=107, M=5.45, S D=.51)$ and teachers $(n=66$, $M=5.45, S D=.41)$ responded to $S E L$ attitudes items, $t(171)=0.01, p=.99$. Cohen's $d$ was .47 , which indicates a small effect size.

Hypothesis 2: An independent samples $t$-test was conducted to compare parent and teacher responses regarding their beliefs of the appropriate balance between SEL and academic subjects in the schools. Higher scores indicate less academic priority and, conversely, more support for the inclusion of SEL. There was not a significant difference between how parents $(n$ $=122, M=4.66, S D=.80)$ and teachers $(n=70, M=4.60, S D=.75)$ responded to academic priority items, $t(190)=-.55, p=.58$. Cohen's $d$ was .78 , indicating a medium effect size.

Hypothesis 3: An independent samples $t$-test was conducted to compare parent and teacher responses regarding their perceptions of the effectiveness of SEL in the schools. The items which loaded onto the SEL effectiveness subscale above 0.40 were averaged together. Higher scores indicate more positive beliefs regarding the positive impacts of SEL on students. There was a significant difference between how parents and teachers rated SEL effectiveness, $t(187)=-2.33, p=.02$. Specifically, parents $(n=119, M=5.45, S D=.57)$ rated $S E L$ effectiveness more highly compared to teachers ( $n=70, M=5.24, S D=.63)$. Cohen's $d$ was 0.59 , indicating a medium effect size.

Hypothesis 4: A one-way ANOVA was conducted to compare teachers with various levels of experience with youth with disabilities in their current classrooms related to $S E L$ 
attitudes. Descriptive analyses revealed that $77 \%$ of respondents were general education teachers with students with disabilities in their classrooms, $12 \%$ were special education teachers, and $9 \%$ were general education teachers without children with disabilities in their classrooms. The numbers of respondents across groups are highly unequal; therefore, results should be interpreted with caution. There was not a significant difference between the three groups related to $S E L$ attitudes, $F(2,56)=.93, p=.40$ : general education teachers without children with disabilities in their classrooms $(n=6, M=5.49, S D=.37)$, general education teachers with children with disabilities in their classrooms $(n=48, M=5.37, S D=.41)$, and special education teachers $(n=$ $8, M=5.58, S D=.42)$. Eta-squared was .03 , indicating a small effect size.

There was also not a significant difference between general education teachers without children with disabilities in their classrooms $(n=6, M=4.77, S D=.75)$, general education teachers with children with disabilities in their classrooms ( $n=48, M=4.43, S D=.76)$, and special education teachers $(n=8, M=4.85, S D=.52)$ related to academic priority, $F(2,59)=$ $1.52, p=.23$. Eta-squared was .05 , indicating a small effect size. Additionally, there was not a significant difference between the three groups related to SEL effectiveness, $F(2,59)=2.75, p=$ .07: general education teachers without children with disabilities in their classrooms $(n=6, M=$ $5.43, S D=.41)$; general education teachers with children with disabilities in their classrooms $(n$ $=48, M=5.11, S D=.66)$; and special education teachers $(n=8, M=5.63, S D=.41)$. Etasquared was .09 , indicating a medium effect size.

An independent samples $t$-test was also conducted to compare parents' scores on $S E L$ attitudes depending on whether they did or did not have children with disabilities. There was not a significant difference between parents without children with disabilities $(n=62, M=5.41, S D$ 
$=.52)$ and parents with one or more children with disabilities $(n=38, M=5.49, S D=.51), t(98)$ $=-0.76, p=.45$. Cohen's $d$ was .52 , indicating a medium effect size.

Independent samples $t$-tests were also conducted to compare parents' scores on $S E L$ effectiveness and academic priority based on their experience with children with disabilities. There was not a significant difference between parents of children without disabilities ( $n=68, M$ $=4.61, S D=.81)$ and parents of one or more children with disabilities $(n=46, M=4.80, S D=$ .76) related to academic priority, $t(112)=-1.24, p=.22$. Cohen's $d$ was .79 , indicating a medium effect size. There was also not a significant difference between parents of children without disabilities $(n=66, M=5.50, S D=.49)$ and parents with one or more children with disabilities $(n=45, M=5.43, S D=.63)$ related to SEL effectiveness, $t(109)=.63, p=.53$. Cohen's $d$ was .55 , indicating a medium effect size.

Hypothesis 5: A one-way ANOVA was conducted to determine whether there was a difference in teacher perceptions of SEL based upon the grade they teach. Teacher responses to an open-ended question asking about the grades they teach were recoded into the following categories: elementary (K-5), middle/junior high (6-8), and high school (9+). Descriptive analyses revealed that $43 \%$ of the teacher respondents taught in a middle/junior high school, $42 \%$ taught in an elementary school, and 14\% taught in a high school. The group sizes are unequal, as high school teachers are underrepresented. Therefore, results should be interpreted with caution.

There was not a significant difference between group ratings of $S E L$ attitudes, $F(2,49)=$ $.66, p=.52$ : elementary school teachers $(n=20, M=5.51, S D=.36)$, middle school teachers $(n$ $=24, M=5.39, S D=.46)$, and high school teachers $(n=8, M=5.54, S D=.35)$. Eta-squared was .03 , indicating a small effect size. There was also not a significant difference between the three groups when considering SEL effectiveness, $F(2,52)=1.70, p=.19$ : elementary school 
teachers $(n=23, M=5.32, S D=.62)$, middle/junior high school teachers $(n=24, M=5.08, S D$ $=.71)$, and high school teachers $(n=8, M=5.53, S D=.45)$. Eta-squared was .06 , indicating a medium effect size. There was a significant difference between groups related to academic priority, $F(2,52)=6.66, p<.001$. According to a Tukey's b post-hoc analysis, middle/junior high school teachers $(n=24, M=4.20, S D=.62)$ scored academic priority lower when compared to both elementary school teachers $(n=23, M=4.86, S D=.66)$ and high school teachers $(n=8, M=4.83, S D=.78)$. Eta-squared was .20 , indicating a large effect size.

Hypothesis 6: An independent samples $t$-test was conducted to compare ratings of $S E L$ attitudes between states with and without SEL mandates for public schools that serve children in kindergarten through twelfth grade. There was not a significant difference between states with statewide SEL mandates $(n=123, M=5.49, S D=.46)$ and those states without statewide SEL mandates $(n=46, M=5.34, S D=.50), t(167)=-1.85, p=.07$. Cohen's $d$ was .47 , indicating a small effect size.

Hypothesis 7: A one-way ANOVA was conducted to determine whether there was a difference in SEL attitudes based on residence in a rural, urban, or suburban area. There was not a significant difference in the scores from individuals from rural $(n=60, M=5.44, S D=.39)$, $\operatorname{urban}(n=36, M=5.47, S D=.50)$, or suburban $(n=76, M=5.44, S D=.53)$ areas, $F(2,169)=$ $.02, p=.98$. Eta-squared was .02 , indicating a small effect size.

An additional one-way ANOVA was conducted to determine whether there was a difference in SEL attitudes based on participant residence in various regions of the United States. There was not a significant difference in scores from individuals located in different regions of the country, $F(4,164)=1.49, p=.21$ : Northeast $(n=4, M=5.49, S D=.38)$, South $(n=11, M=$ 
5.46, $S D=.36)$, Midwest $(n=138, M=5.48, S D=.46)$, West $(n=15, M=5.16, S D=.65)$, and Pacific $(n=1, M=5.44, S D=\mathrm{N} / \mathrm{A})$. Eta-squared was .04 , indicating a small effect size. 


\section{CHAPTER V: DISCUSSION}

I set out to create and validate a measure of parent and teacher perceptions of SEL in the schools. All 50 original items were retained on the final SEL attitudes scale, as they loaded highly onto one underlying construct. Although the hypothesized five-factor structure was not supported, the results of this dissertation indicate that the five domains of SEL as set forth by CASEL all measure related skills and behaviors (i.e., social and emotional competence). Additionally, nine of the ten original items on the SEL effectiveness scale and all ten original items on the academic priority scale were retained. Results also indicate that all three subscales are significantly correlated with one another. This dissertation adds to the literature by demonstrating that social-emotional skills are highly interrelated as well as creating and validating scales of parent and teacher beliefs about SEL.

The results of this study add to the literature regarding parent and teacher beliefs about social-emotional learning. Past research has indicated that parents' attitudes toward SEL are typically less positive when compared to teachers' attitudes (Burleson et al., 1980; Calkins, 2019). Results of the current study indicate that parent and teacher perceptions of SEL inclusion and the belief that SEL should be given the same priority as academic subjects are not disparate from one another, contrasting with previous research. These results are promising when considering the positive impacts of home-school collaboration, such as positive behaviors and academic achievement in youth (Sheridan et al., 2004). If parent and teacher attitudes toward SEL are similarly positive, it is more likely that youth will be supported similarly across settings via congruence between parent and teacher behaviors in supporting social-emotional skills. Parents in the current study responded significantly more positively to items regarding the beliefs of the efficacy of SEL in the schools compared to teachers; these results may indicate that 
parents are becoming more aware of the benefits of including SEL in the schools and recognize that school is an important location for youth to learn and practice social and emotional skills (Calkins, 2019).

The results of this study also indicate that individual perceptions of the importance of SEL inclusion in the schools, the priority placed on SEL in relation to academics, and perceptions of SEL effectiveness do not differ based on experience with individuals with disabilities. Past research has indicated that teachers with exposure to children with and without disabilities in the same classroom may rate the importance of SEL more highly compared to special education teachers or general education teachers without children with disabilities in their classrooms (Kwon et al., 2011). It is important to note that, consistent with Calkins (2019), the number of general education teachers without students with disabilities in their classrooms is extremely low in comparison to general education teachers with children with disabilities in their classrooms; these data likely reflect the fact that schools are utilizing an inclusive framework for students with disabilities. When using an inclusive framework, most general education teachers have experience with students with disabilities who are part of their classroom for part of or the full school day. Therefore, the distinction between classroom compositions may be obsolete. Additionally, the results of the current study could indicate that all teachers, regardless of classroom composition, understand the importance of SEL and, thus, have similar beliefs regardless of experience with students with disabilities. However, the means calculated in this study approach significance in an unexpected direction: special education teachers had higher ratings compared to general education teachers with and without youth with disabilities in their classrooms. These data could indicate that experience with disabilities in a more restrictive setting sensitizes teachers to individual needs and leads to more positive beliefs about SEL. 
The results of this study pertaining to parents and their level of experience with youth with disabilities trends in the expected direction, consistent with past research (Spann et al., 2003), such that parents of children with disabilities had more positive SEL attitudes compared to parents of children without disabilities. However, the differences were not statistically significant. These results indicate that parents have similarly positive beliefs regarding SEL, its impact, and its inclusion alongside academic instruction regardless of their child's specific deficits or needs. These data could further indicate that parents have a better understanding of SEL and its benefits for all youth.

Past research indicates that teachers of junior high and high school aged youth are less supportive of SEL when compared to teachers of elementary-aged youth (Bridgeland et al., 2013). The current study found that middle/ junior high school teachers placed the least amount of priority on including SEL along with academic subjects when compared to elementary school teachers and high school teachers. These results indicate that, consistent with past research, teacher support for SEL for youth in elementary grades remains high. However, as youth age, it is likely that teachers believe that students have adequate social and emotional competence and have difficulties identifying ongoing targets for SEL.

This study also explored whether SEL mandates were associated with more positive attitudes toward SEL. Although there was not a significant difference, the data trended in the direction which indicates that individuals who resided in states with SEL mandates for youth in kindergarten and above may have more positive beliefs about SEL. These data demonstrate that state-based SEL mandates may translate into increased understanding about SEL amongst parents and teachers residing in those states, perhaps due to increased communication of 
information across settings. This information could include specific school- and classroom-level SEL practices, the benefits of SEL, or how SEL can impact academic performance.

Finally, there were no differences in SEL ratings based upon geographical location or residence in a rural, urban, or suburban region. These results may indicate that beliefs about SEL are consistent across the United States which could reflect exosystem-level national norms and cultural values.

This study has several limitations. One major limitation of this study is its small sample size. As indicated previously, approximately 150 parents and 150 teachers were needed in order to carry out an adequate factor analysis (Mundfrom et al., 2005); the final sample in the current study only consisted of 122 parents and 70 teachers. Researchers have indicated that small sample sizes can lead to biased estimates; however, it is important to note that small samples may be appropriate as the structure coefficients in the current factor analyses were high (Kahn, 2006). The teacher sample size was particularly small; this small sample size influenced the researchers' abilities to examine hypotheses meaningfully. For example, the analyses exploring potential differences in teacher responses based upon their experience with youth with disabilities in their classroom as well as what grade they taught revealed unequal group sizes. Future research should work to increase teacher sample size in order to gain a more representative sample as well as sufficient power for analyses.

Another limitation of this study is its recruitment methods. Snowball sampling was primarily utilized to recruit participants; the sample of respondents may not be representative of the population, as individuals who chose to participate were likely interested in the topic of SEL and were thus motivated to send it to others who may have also been interested in the topic of SEL. Additionally, the majority of respondents were located in Illinois; future research should 
gather more representative samples of both parents and teachers in order to obtain more representative data. More representative data lead to more helpful insights into potential policy change as well as scale validity.

Finally, this study was conducted during the COVID-19 pandemic. Individuals were concerned about students' lack of exposure to "typical" school and classroom structure. These concerns likely impacted participants' responses, as many people were worried about the lack of socialization for youth due to recommended "social distancing" practices. Researchers have discussed how the closure of schools and the maintenance of social distancing practices likely influenced youth by disrupting their routine, increasing familial stress, and decreasing the availability of social supports. Studies that have been conducted since the onset of the COVID19 pandemic indicate that youth have experienced increased difficulties with emotion regulation, including heightened levels of anxiety, depression, stress, and suicidality (De France et al., 2021; Nearchou et al., 2020). Research has also indicated that the pandemic has impacted the social lives of youths such that youth may perceive less support from friends, which in turn leads to increased psychological distress (Rogers et al., 2021). Online learning may have had a negative impact on the development of social skills as well as academic performance, which reflects research that has demonstrated the link between social-emotional competence and increased academic performance - as mediated by positive mental health (Panayiotou et al., 2019). Although youth perceived decreased social connectedness with their peers, other data indicates that some youth reported increased familial support and cohesiveness (Rogers et al., 2021). These data may indicate that parental relationships were strengthened during the pandemic, and parents may have been more in-tune with their children's needs. This increase in cohesiveness 
among family members may have led to higher ratings of the importance of social-emotional learning by parents for the current study.

There are many future directions highlighted by this study. First of all, the final SEL attitudes scale included all 50 original items. Future research should attempt to identify the most important items that would continue to yield high reliability and validity in order to shorten this scale. A shorter scale would be more manageable for use as a tool for other researchers and school personnel. Analyses revealed that the academic priority scale did not correlate significantly with the single item derived from the TASEL but had high validity (Schultz et al., 2010). The SEL effectiveness scale did correlate significantly with the scale derived from the TASEL and had high validity. The three scales outlined in this dissertation should be further validated using additional samples, and convergent validity should be assessed using other existing SEL attitude scales. Furthermore, future researchers can use these scales to explore potential differences among beliefs about SEL in the schools along a variety of variables, including experience with youth with disabilities, differing roles within the school community (teacher, school psychologist, student, principal, etc.), and socioeconomic status.

Future research should further investigate parent and teacher attitudes toward SEL in the schools to ensure that important stakeholders in youth's lives understand the importance of SEL inclusion. Additionally, future research could expand on the congruence between parent and teacher behaviors across settings (e.g. school and home) to determine whether similar attitudes toward SEL lead to similar SEL-supportive behaviors. This dissertation focused only on the school environment and how parent and teacher attitudes toward SEL in the schools interact at the mesosystem-level; researchers could investigate SEL instruction and support that occurs 
within the homes to expand on the impact of attitudes on behaviors across settings related to SEL supports.

The data of the current study related to state-level SEL mandates and the relation to SEL beliefs trended in the expected direction: individuals residing in states with SEL mandates for youth in grades kindergarten through twelfth grade had more positive attitudes toward the inclusion of SEL in the schools. Future research should investigate this potential factor, as these data could support the creation of SEL-specific goals in states that have not yet adopted their own SEL mandates to further support positive perceptions of SEL and its importance in the schools.

Research suggests that including SEL in the schools has myriad positive impacts on children's wellbeing and academic success. This study adds to the literature by creating and validating a scale of parent and teacher attitudes toward SEL in the schools. This scale could be utilized by future researchers as well as school stakeholders interested in assessing beliefs about SEL among its teachers and parents. Additionally, this research suggests that parent and teacher attitudes toward SEL may not be as disparate as once thought; these data indicate that SEL may be more well understood across parents and teachers than previously imagined. Ensuring that both parents and teachers understand the purposes and outcomes of including SEL will likely continue to ensure that attitudes remain positive for both parent and teacher across a number of variables, including grade level that a teacher teaches, region and/or state, and experience with children with disabilities. These positive attitudes toward SEL may lead to increased support for SEL in the schools, which may enhance outcomes for youth along social and emotional competence domains. 


\section{REFERENCES}

Aber, J. L., Jones, S. B., Brown, J. L., Chaudry, N., \& Samples, F. (2002). Resolving conflict creatively: Evaluating the developmental effects of a school-based violence prevention program in neighborhood and classroom context. Development and Psychopathology, 10, 187-213. doi:10.1017/S0954579498001576

American Psychiatric Association (2013). Diagnostic and Statistical Manual of Mental Disorders, $5^{\text {th }}$ Ed. Washington DC: American Psychiatric Publishing.

Ashdown, D. M. \& Bernard, M. E. (2012). Can explicit instruction in social and emotional learning skills benefit the social-emotional development, well-being, and academic achievement of young children? Early Childhood Education Journal, 39, 397-405. doi: https://doi.org/10.1007/s10643-011-0481-x

Begeer, S., Koot, H. M., Rieffe, C., Terwogt, M. M., \& Stegge, H. (2008). Emotional competence in children with autism Diagnostic criteria and empirical evidence. Developmental Review, 28, 342-369. https://doi.org/10.1016/j.dr.2007.09.001

Bender, W. N. \& Wall, M. E. (1994). Social-emotional development of students with learning disabilities. Learning Disability Quarterly, 17(4), 323-341. https://doi.org/10.2307 $\% 2 \mathrm{~F} 1511128$

Berkovits, L. D. \& Baker, B. L. (2014). Emotion dysregulation and social competence: Stability, change and predictive power. Journal of Intellectual Disability Research, 58(8), 756-776. https://doi.org/10.1111/jir.12088 
Bierman, K. L. \& Motamedi, M. (2015). Social-emotional learning programs for preschool children. In J. Durlak, C. Domitrovich, R. P. Weissberg, and T. Gullotta (Eds.) The Handbook of Social and Emotional Learning: Research and Practice. New York, NY: Guilford.

Blair, B. L., Perry, N. B., O’Brien, M., Calkins, S. D., Keane, S. P., \& Shanahan, L. (2015). Identifying developmental cascades among differentiated dimensions of social competence and emotion regulation. Developmental Psychology, 51(8), 1062-1073. https://psycnet.apa.org/doi/10.1037/a0039472

Brackett, M. A., Reyes, M. R., Rivers, S. E., Elbertson, N. A., \& Salovey P. (2012). Assessing teachers' beliefs about social and emotional learning. Journal of Psychoeducational Assessment, 30(3), 219-236. https://doi.org/10.1177\%2F0734282911424879

Bridgeland, J., Bruce, M., \& Hariharan, A. (2013). The missing piece: A national teacher survey on how social and emotional learning can empower children and transform schools. Collaborative for Academic, Social, and Emotional Learning. Chicago: Author.

Bronfenbrenner, U. (1977). Toward an experimental ecology of human development. American Psychologist, 32(7), 513-531. https://psycnet.apa.org/doi/10.1037/0003-066X.32.7.513

Buchanan, R., Gueldner, B. A., Tran, O. K., \& Merrell, K. W. (2009). Social and emotional learning in classrooms: A survey of teachers' knowledge, perceptions, and practices. Journal of Applied School Psychology, 25, 187-203. https://doi.org/10.1080/1537 7900802487078

Buckley, M., Storino, M., \& Saarni, C. (2003). Promoting emotional competence in children and adolescents: Implications for school psychologists. School Psychology Quarterly, 18(2), 177-191. https://psycnet.apa.org/doi/10.1521/scpq.18.2.177.21855 
Burleson, B., Nelson, R., \& Tollefson, N. (1980). Elementary teachers' and mothers' attitudes toward affective education. Elementary School Guidance and Counseling, 15(2), 147151. http://www.jstor.org/stable/24009054

Calkins, H. M. (2019). Parent and teacher perceptions of the importance of social-emotional learning in the schools (Master's thesis, Illinois State University). ProQuest.

Carroll, I., Sarah, F., David, S., Allison, M., Brian, A., \& Eric, Y. (2001). Emotion knowledge as a predictor of social behavior and academic competence in children at risk. Psychological Science, 12(1), 18. https://doi.org/10.1111\%2F1467-9280.00304

CASEL (2019). Core SEL competencies. Retrieved August 5, 2019, from http://www.casel.org/core-competencies.

CASEL (n.d.). CASEL-AIR staff survey of SEL implementation. https://casel.org/resourcessupport/.

Cavell, T. A. (1990). Social adjustment, social performance, and social skills: A tri-component model of social competence. Journal of Clinical Child Psychology, 19(2), 111-122. https://doi.org/10.1207/s15374424jccp1902_2

Ciarrochi, J., Morin, A., Sahdra, B. K., Litalien, D., \& Parker, P. D. (2017). A longitudinal person-centered perspective on youth social support: Relations with psychological wellbeing. Developmental Psychology, 53(6), 1154-1169. https://psycnet.apa.org/doi/10. 1037/dev0000315

Clark, L. A. \& Watson, D. (1995). Constructing validity: Basic issues in objective scale development. Psychological Assessment, 7(3), 309-319. https://psycnet.apa.org/doi/10. $1037 / 14805-012$ 
Colton, D. \& Covert, R. W. (2007). Designing and Constructing Instruments for Social Research and Evaluation. San Francisco, CA: Jossey-Bass.

Cowan, R. J., Swearer Napolitano, S. M., \& Sheridan, S. M. (2004). Home-school collaboration. In C. D. Spielberger (Eds.), Encyclopedia of Applied Psychology, Volume 2 (201-208). Oxford: Elsevier.

Crawford, A. M. \& Manassis, K. (2011). Anxiety, social skills, friendship quality, and peer victimization: An integrated model. Journal of Anxiety Disorders, 25(7), 924-931. https://doi.org/10.1016/j.janxdis.2011.05.005

De France, K., Hancock, G. R., Stack, D. M., Serbin, L. A., \& Hollenstein, T. (2021). The mental health implications of COVID-19 for adolescents: Follow-up of a four-wave longitudinal study during the pandemic. American Psychologist. Advance online publication. http://dx.doi.org/10.1037/amp0000838

Dodge, K. A. (1986). A social information processing model of social competence in children. In M. Perlmutter (Ed.), Minnesota Symposium on Child Psychology, Vol. 18: Cognitive perspectives on children's social and behavioral development (pp 77-125). Hillsdale, NJ: Erlbaum.

Durlak, J. A., Weissberg, R. P., Dymnicki, A. B., Taylor, R. D., \& Schellinger, K. B. (2011). The impact of enhancing students' social and emotional learning: A meta-analysis of schoolbased universal interventions. Child Development, 82(1), 405-432. https://doi.org/ 10.1111/j.1467-8624.2010.01564.x

Elias, M. J. (2004). The connection between social-emotional learning and learning disabilities: Implications for intervention. Learning Disability Quarterly, 27, 53-63. https://doi.org $/ 10.2307 \% 2 \mathrm{~F} 1593632$ 
Espelage, D. L., Rose, C. A., \& Polanin, J. R. (2016). Social-emotional learning program to promote prosocial and academic skills among middle school students with disabilities. Remedial and Special Education, 37(6), 323-332. https://doi.org/10.1177\%2 F0741932515627475

Garner, P. W. \& Estep, K. M. (2001). Emotional competence, emotion socialization, and young children's peer-related social competence. Early Education and Development, 12(1), 2948. https://doi.org/10.1207/s15566935eed1201_3

Greenberg, M. T., Domitrovich, C. E., Graczyk, P. A., Zins, J. E. (2005). The Study of Implementation in School-Based Preventive Interventions: Theory, Research, and Practice (Volume 3). Rockville, MD: Center for Mental Health Services, Substance Abuse and Mental Health Services Administration.

Greitemeyer, T. \& Sagioglou, C. (2018). Does low (vs. high) subjective socioeconomic status increase both prosociality and aggression? Social Psychology, 49(2), 76-87. https://doi.org/10.1027/1864-9335/a000331

Guralnick, M. J. (2010). Early intervention approaches to enhance the peer-related social competence of young children with developmental delays. Infants and Young Children, 23(2), 73-83. https://dx.doi.org/10.1097\%2FIYC.0b013e3181d22e14

Henricsson, L. \& Rydell, A. M. (2006). Children with behaviour problems: The influence of social competence and social relations on problem stability, school achievement and peer acceptance across the first six years of school. Infant and Child Development, 15, 347366. https://doi.org/10.1002/icd.448

Hinde, R. A. (1987). Individuals, relationships and culture: Links between ethology and the social sciences. New York, NY: Cambridge University Press. 
Hosokawa, R. \& Katsura, T. (2017). A longitudinal study of socioeconomic status, family processes, and child adjustment from preschool until early elementary school: The role of social competence. Child and Adolescent Psychiatry and Mental Health, 11(62), 1-28. https://doi.org/10.1186/s13034-017-0206-z

Hubbard, J. A. \& Coie, J. D. (1994). Emotional correlates of social competence in children's peer relationships. Merrill-Palmer Quarterly, 40, 1-20. https://www.jstor.org/stable/ 23087905

Hughes, J. N., Cavell, T. A., Meehan, B. T., Zhang, D., \& Collie, C. (2005). Adverse school context moderates the outcomes of selective interventions for aggressive children. Journal of Consulting and Clinical Psychology, 73(1), 731-736. https://psycnet.apa. org/doi/10.1037/0022-006X.73.4.731

Iacobucci, D. (2001). How high or low must loadings be to keep or delete a scale item? Journal of Consumer Psychology, 10(1), 75-82.

Jones, D. E., Greenberg, M., \& Crowley, M. (2015). Early social-emotional functioning and public health: The relationship between kindergarten social competence and future wellness. American Journal of Public Health, 105(11), 2283-2290. https://ajph. aphapublications.org/doi/abs/10.2105/AJPH.2015.302630

Kahn, J. (2006). Factor analysis in counseling psychology research, training, and practice: Principles, advances, and applications. The Counseling Psychologist, 34(5), 684-718. $10.1177 / 0011000006286347$ 
Kam, C. M., Greenberg, M. T., \& Kusché (2004). Sustained effects of the PATHS curriculum on the social and psychological adjustment of children in special education. Journal of Emotional and Behavioral Disorders, 12(2), 66-78. https://doi.org/10.1177\% 2F10634266040120020101

Kwon, K. A., Elicker, J., \& Kontos, S. (2011). Social IEP objectives, teacher talk, and peer interaction in inclusive and segregated preschool settings. Early Childhood Education Journal, 39, 267-277. https://doi.org/10.1007/s10643-011-0469-6

Lindsay, G., Ricketts, J., Peacey, L. V., Dockrell, J. E., \& Charman, T. (2016). Meeting the educational and social needs of children with language impairment or autism spectrum disorder: The parents' perspective. International Journal of Language and Communication Disorders, 51(5), 495-507. https://doi.org/10.1111/1460-6984.12226

Mahoney, G., \& Wiggers, B. (2007). The role of parents in early intervention: Implications for social work. Children and Schools, 29(1), 7-15. https://doi.org/10.1093/cs/29.1.7

Matthews, B. L., Kochn, A. J., Abtahi, M. M., \& Kerns, K. A. (2016). Emotional competence and anxiety in childhood and adolescence: A meta-analytic review. Clinical Child and Family Psychology Review, 19(2), 162-184. https://doi.org/10.1007/s10567-016-0204-3

McCabe, P. C. \& Meller, P. J. (2004). The relationships between language and social competence: How language impairment affects social growth. Psychology in the Schools, 41(3), 313-321. https://doi.org/10.1002/pits.10161

Meyers, A. B. \& Hickey, A. M. (2014). Multilevel prospective dynamics in school-based social and emotional learning programs. Journal of Cognitive Education and Psychology, 13(2), 218-231. 10.1891/1945-8959.13.2.218 
Mundfrom, D. J., Shaw, D. G., Ke, T. L. (2005). Minimum sample size recommendations for conducting factor analyses. International Journal of Testing, 5(2), 159-168. https://doi.org/10.1207/s15327574ijt0502_4

Nearchou, F., Flinn, C., Niland, R., Subramaniam, S. S., \& Hennessy, E. (2020). Exploring the impact of COVID-19 on mental health outcomes in children and adolescents: A systematic review. Journal of Environmental Research and Public Health, 17 (8479). 10.3390/ijerph17228479.

Normand, S., Schneider, B., Lee, M., Maisonneuve, M., Kuehn, S., \& Robaey, P. (2011). How do children with ADHD (mis) manage their real-life dyadic friendships? A multi-method investigation. Journal of Abnormal Child Psychology, 39, 293-305. https://doi.org/10. 1007/s10802-010-9450-X

Nowicki, E. A. (2003). A meta-analysis of the social competence of children with learning disabilities compared to classmates of low and average to high achievement. Learning Disability Quarterly, 26, 171-188. https://doi.org/10.2307\%2F1593650

Panayiotou, M., Humphrey, N., \& Wigelsworth, M. (2019). An empirical basis for linking social and emotional learning to academic performance. Contemporary Educational Psychology, 56, 193-204. https://doi.org/10.1016/j.cedpsych.2019.01.009

Pierce-Jordan, S. \& Lifter, K. (2005). Interaction of social and play behaviors in preschoolers with and without pervasive developmental disorder. Topics in Early Childhood Special Education, 25(1), 34-47. https://doi.org/10.1177\%2F02711214050250010401

Pochon, R. \& Declerq, C. (2014). Emotional lexicon understanding and emotion recognition: A longitudinal study in children with Down Syndrome. Journal of Developmental and Physical Disabilities, 26, 549-563. https://doi.org/10.1007/s10882-014-9380-6 
Raver, C. C. (2004). Placing emotional self-regulation in sociocultural and socioeconomic contexts. Child Development, 75(2), 346-353. https://doi.org/10.1111/j.14678624.2004.00676.x

Rogers, A. A., Ha, T., \& Ockey, S. (2021). Adolescents' perceived socio-emotional impact of COVID-19 and implications for mental health: Results from a U.S.-based mixed-methods study. Journal of Adolescent Health, 68, 43-52. https://doi.org/10.1016/j.jadohealth.2020. 09.039

Rose-Krasnor, L. (1997). The nature of social competence: A theoretical review. Social Development, 6(1), 111-135. https://doi.org/10.1111/j.1467-9507.1997.tb00097.x

Rydell, A. M., Thorell, L. B., \& Bohlin, G. (2007). Emotion regulation in relation to social functioning: An investigation of child self-reports. European Journal of Developmental Psychology, 4(3), 293-313. https://doi.org/10.1080/17405620600783526

Saarni, C. (1999). The development of emotional competence. New York, NY: The Guilford Press.

Sarason, B. R. (1981). The dimensions of social competence: Contributions from a variety of research areas. In J. D. Wine \& M. D. Smye (Eds.), Social competence. New York: Guilford Press.

Sater, G. M. \& French, D. C. (1989). A comparison of the social competencies of learning disabled and low achieving elementary-aged children. The Journal of Special Education, 23(1), 29-42. https://doi.org/10.1177\%2F002246698902300104

Schonert-Reichl, K. A. (2017). Social and emotional learning and teachers. The Future of Children, 27(1), 137-155. https://www.jstor.org/stable/44219025 
Schonfeld, D. J., Adams, R. E., Fredstrom, B. K., Weissberg, R. P., Gilman, R., Voyce, C. ... \& Speese-Linehan, D. (2015). Cluster-randomized trial demonstrating impact on academic achievement of elementary social-emotional learning. School Psychology Quarterly, 30(3), 406-420. https://psycnet.apa.org/doi/10.1037/spq0000099

Schultz, D., Ambike, A., Stapleton, L. M., Domitrovich, C. E., Schaeffer, C. M., \& Bartels, B. (2010). Development of a questionnaire assessing teacher perceived support for and attitudes about social and emotional learning. Early Education and Development, 21(6), 865-885. https://doi.org/10.1080/10409280903305708

Semrud-Clikeman, M. \& Schafer, V. (2000). Social and emotional competence in children with ADHD and/or learning disabilities. Journal of Psychotherapy in Independent Practice, 1(4), 3-19. https://doi.org/10.1300/J288v01n04_02

Sheridan, S. M., Hungelman, A., \& Maughan, D. P. (1999). A contextualized framework for social skills assessment, intervention, and generalization. School Psychology Review, 28(1), 84-103. https://doi.org/10.1080/02796015.1999.12085950

Sheridan, S. M., Warnes, E. D., \& Dowd, S. (2004). Home-school collaboration and bullying: An ecological approach to increase social competence in children and youth. In D. L. Espelage \& S. M. Swearer (Eds.), Bullying in American schools: A social-ecological perspective on prevention and intervention (245-268). Mahwah, NJ: Lawrence Erlbaum Associates.

Spann, S. J., Kohler, F. W., \& Soenksen, D. (2003). Examining parents' involvement in and perception of special education services: An interview with families in a parent support group. Focus on Autism and Other Developmental Disabilities, 18(4), 228-237. https://doi.org/10.1177\%2F10883576030180040401 
Stellar, J. E., Manzo, V. M., Kraus, M. W., \& Keltner, D. (2012). Class and compassion: Socioeconomic factors predict response to suffering. Emotion, 12, 449-459. https://psycnet.apa.org/doi/10.1037/a0026508

Stepp, S. D., Pardini, D. A., Loeber, R., \& Morris, N. A. (2011). The relation between adolescent social competence and young adult delinquency and educational attainment among at-risk youth: The mediating role of peer delinquency. The Canadian Journal of Psychiatry, 56(8), 457-465. https://doi.org/10.1177\%2F070674371105600803

Thorell, L. B. \& Rydell, A. M. (2008). Behaviour problems and social competence deficits associated with symptoms of attention-deficit/ hyperactivity disorder: Effects of age and gender. Child: Care, Health and Development, 34(5), 584-595. https://doi.org/10.1111/ j.1365-2214.2008.00869.x

Wellner, L. (2012). Building parent trust in the special education setting. Leadership, 41(4), 1619.

Yagmurlu B. \& Yavuz, H. M. (2015). Social competence and temperament in children with chronic orthopaedic disability. International Journal of Disability, Development and Education, 62(1), 83-93. https://doi.org/10.1080/1034912X.2014.984590

Zeedyk, S. M., Cohen, S. R., Eisenhower, A., \& Blacjer, J. (2016). Perceived social competence and loneliness among young children with ASD: Child, parent, and teacher reports. Journal of Autism and Developmental Disorders, 46(2), 436-449. https://doi.org/10.1007/ s10803-015-2575-6

Zhai, F., Raver, C. C., \& Jones, S. M. (2015). Social and emotional learning services and child outcomes in third grade: Evidence from a cohort of Head Start participants. Children and Youth Services Review, 56, 42-51. https://doi.org/10.1016/j.childyouth.2015.06.016 
Zinsser, K. M., Shewark, E. A, Denham, S. A., \& Curby. T. W. (2014). A mixed-method examination of preschool teacher beliefs about social-emotional learning and relations to observed emotional support. Infant and Child Development, 23, 471-493.

https://doi.org/10.1002/icd.1843 


\section{APPENDIX A: INITIAL SURVEY}

\section{SEL Attitudes}

"Within the schools, children should be taught to..."

\section{$\underline{\text { Self-Awareness }}$}

1. ... identify their own emotions.

2. ... recognize their own strengths.

3. ... develop self-confidence.

4. ... develop self-efficacy.

5. ... identify their own thoughts.

6. ... understand how their thoughts influence their behavior.

7. ... understand how their feelings influence their behavior.

8. ... identify their personal values and beliefs.

9. ... understand how emotions make their bodies feel (e.g. "butterflies" in their stomach when excited or nervous, clenched fists and tense when angry or scared).

10. ... develop a sense of optimism about their futures.

\section{$\underline{\text { Self-management }}$}

1. ... regulate their own behaviors.

2. ... regulate their feelings.

3. ... control their thoughts.

4. ... manage their stress. 
5. ... set goals for themselves.

6. $\ldots$ organize their materials.

7. ... motivate themselves to reach their goals.

8. ... develop self-discipline in order to reach their goals.

9. ... control their impulses.

10. ... successfully monitor one's own progress toward reaching a goal.

\section{$\underline{\text { Social Awareness }}$}

1. ... take the perspective of others in various situations.

2. ... understand others' emotions.

3. ... appreciate diversity.

4. ... display empathy toward others.

5. ... demonstrate respect for others.

6. ... understand social norms for behavior.

7. ... recognize social supports available to them, such as family, school, and community.

8. ... shows concern for the feelings of others.

9. ... recognize that their behaviors affect others.

10. ... understand nonverbal communication such as tone of voice and body language.

\section{$\underline{\text { Relationship skills }}$}

1. ... establish positive relationships with others.

2. ... initiate interactions with others.

3. ... maintain positive relationships. 
4. ... cooperate with others.

5. ... negotiate through conflicts.

6. ... effectively communicate their needs.

7. ... be kind toward others.

8. ... effectively listen to others.

9. ... effectively express their emotions.

$10 . .$. be able to reciprocate during social interactions.

\section{$\underline{\text { Responsible Decision-Making }}$}

1. ... identify problems.

2. ... analyze problem situations.

3. ... generate possible solutions to problems.

4. ... consider consequences of possible decisions.

5. ... evaluate the effectiveness of their decisions.

6. ... consider the well-being of the self in decision-making.

7. ... consider the well-being of others in decision-making.

8. ... accept responsibility for their actions.

9. ... ask for help when needed in making decisions.

10. ... think about previous experiences with similar dilemmas and how they impact decision-making.

\section{Academic Priority}

1. Attention to SEL takes too much time away from academics. 
2. Overall, academics are more important than SEL.

3. Instruction in reading is more important than SEL.

4. Instruction in math is more important than SEL.

5. Academics must take priority over SEL for the sake of standardized testing.

6. There needs to be a better balance between SEL and academics.

7. Schools should support the whole student, including academics and social, emotional, and behavioral development.

8. The school's primary job is to teach academic subjects.

9. SEL does not belong in the schools.

10. Students should learn SEL in other contexts and not within the school.

\section{SEL Effectiveness}

1. SEL is effective in helping children learn social skills.

2. SEL is effective in helping children learn about emotions.

3. SEL positively impacts academic achievement.

4. Schools are a natural site of exposure to SEL, so it should be addressed in the schools.

5. SEL is only effective for students who need it.

6. SEL positively impacts school climate.

7. SEL can be effective for students with and without disabilities.

8. SEL can be effective for students of all racial and ethnic identities.

9. SEL can be effective for students from all income levels.

10. SEL can be effective for students of all grades from kindergarten to twelfth grade. 


\section{TASEL: Academic Priority}

1. The principal gives more importance to learning academics than learning social and emotional skills.

\section{TASEL: Program Effectiveness}

1. SEL programs are effective in helping children learn social and emotional skills.

2. It is worth teachers' effort to implement SEL lessons.

3. SEL has helped my children to improve their social and emotional skills.

4. SEL can help all kids regardless of their temperament.

\section{Demographic Questions}

1. Please indicate whether you completed this survey as a teacher or a parent.

a. If you are a teacher, please indicate the grade with which you work.

2. Please indicate the statement that best represents you and your level of experience with children with disabilities.

a. General education teacher without children with disabilities in my classroom

b. General education teacher with children with disabilities in my classroom

c. Special education teacher / teacher of a self-contained classroom / teacher of a functional, life-skills classroom

d. Parent of a child / children without disabilities

e. Parent of one or more children with disabilities

f. Other: Please indicate

3. Please indicate your racial/ethnic identity. 

a. African American
b. American Indian
c. Asian American
d. Hispanic/Latino(a)
e. White
f. Prefer not to respond
g. Other

4. Please indicate your gender.
a. Male
b. Female
c. Transgender
d. Prefer not to respond
e. Other

5. Please indicate your age.

6. In which state do you live?

7. Please indicate whether you live in a rural, suburban, or urban region. 


\section{APPENDIX B: FINAL ITEMS ON SCALES AFTER FACTOR ANALYSIS}

\section{SEL Attitudes}

1. ... identify their own emotions.

2. ... recognize their own strengths.

3. ... develop self-confidence.

4. ... develop self-efficacy.

5. ... identify their own thoughts.

6. ... understand how their thoughts influence their behavior.

7. ... understand how their feelings influence their behavior.

8. ... identify their personal values and beliefs.

9. ... understand how emotions make their bodies feel (e.g. "butterflies" in their stomach when excited or nervous, clenched fists and tense when angry or scared).

10. ... develop a sense of optimism about their futures.

11... regulate their own behaviors.

12. ... regulate their feelings.

13. ... control their thoughts.

14. ... manage their stress.

15. ... set goals for themselves.

16. ... organize their materials.

17. ... motivate themselves to reach their goals.

18. ... develop self-discipline in order to reach their goals.

19. ... control their impulses.

20. ... successfully monitor one's own progress toward reaching a goal. 
21.... take the perspective of others in various situations.

22. ... understand others' emotions.

23. ... appreciate diversity.

24. ... display empathy toward others.

25. ... demonstrate respect for others.

26. ... understand social norms for behavior.

27. ... recognize social supports available to them, such as family, school, and community.

28. ... shows concern for the feelings of others.

29. ... recognize that their behaviors affect others.

30. ... understand nonverbal communication such as tone of voice and body language.

31... establish positive relationships with others.

32. ... initiate interactions with others.

33. ... maintain positive relationships.

34. ... cooperate with others.

35.... negotiate through conflicts.

36. ... effectively communicate their needs.

37. ... be kind toward others.

38. ... effectively listen to others.

39. ... effectively express their emotions.

$40 . .$. be able to reciprocate during social interactions.

41.... identify problems.

42. ... analyze problem situations.

43. ... generate possible solutions to problems.

44. ... consider consequences of possible decisions. 
45. ... evaluate the effectiveness of their decisions.

46. ... consider the well-being of the self in decision-making.

47. ... consider the well-being of others in decision-making.

48. ... accept responsibility for their actions.

49. ... ask for help when needed in making decisions.

$50 . .$. think about previous experiences with similar dilemmas and how they impact decision-making.

\section{SEL Effectiveness}

1. Social-emotional learning positively impacts academic achievement.

2. Social-emotional learning is effective for students from all income levels.

3. Social-emotional learning is effective for students of all grades, kindergarten through twelfth grade.

4. Social-emotional learning is effective for students of all racial and ethnic identities.

5. Social-emotional learning is effective in helping children learn social skills.

6. Social-emotional learning is effective for students with and without disabilities.

7. Social-emotional learning is effective in helping children learn about emotions.

8. Social-emotional learning positively impacts school climate.

9. Schools are natural sites of exposure to social-emotional learning, so it should be addressed in the schools.

\section{Academic Priority}

1. Overall, academics are more important than social-emotional learning. 
2. Instruction in reading is more important than social-emotional learning.

3. Instruction in math is more important than social-emotional learning.

4. Social-emotional learning doesn't belong in the schools.

5. Attention to social-emotional learning takes too much time away from academics.

6. The school's primary job is to teach academic subjects.

7. Schools should support the whole student, including academics and social, emotional, and behavioral development.

8. Social-emotional learning should be given the same amount of instructional time as academics.

9. Academics must take priority over social-emotional learning for the sake of standardized testing.

10. Social-emotional learning should be addressed in other contexts and not within the school. 


\section{APPENDIX C: TABLES AND FIGURES}

Table 1. Percent of Respondents Across States

State Percent of Respondents

\begin{tabular}{ll}
\hline Alaska & 0.5 \\
Arizona & 0.5 \\
California & 1.6 \\
Colorado & 5.3 \\
Connecticut & 0.5 \\
Florida & 0.5 \\
Georgia & 1.1 \\
Illinois & 65.8 \\
Indiana & 0.5 \\
Iowa & 4.3 \\
Kansas & 0.5 \\
Kentucky & 1.6 \\
Maine & 2.1 \\
Maryland & 0.5 \\
Minnesota & 1.6 \\
Missouri & 3.2 \\
Nebraska & 2.1 \\
Nevada & 1.1 \\
New York & 0.5 \\
Ohio & 1.1 \\
Oregon & 0.5 \\
Texas & 1.6 \\
Virginia & 0.5 \\
Washington & 0.5 \\
Wisconsin & 1.6 \\
\hline
\end{tabular}

Table 2. Percent of Respondents Across Geographical Regions

\begin{tabular}{llll} 
Geographical Region & $\begin{array}{l}\text { Percent of Total } \\
\text { Respondents }\end{array}$ & $\begin{array}{l}\text { Percent of Parent } \\
\text { Respondents }\end{array}$ & $\begin{array}{l}\text { Percent of Teacher } \\
\text { Respondents }\end{array}$ \\
\hline Northeast & 3.2 & $4.1 \%$ & $1.4 \%$ \\
South & 5.9 & $8.2 \%$ & $1.4 \%$ \\
Midwest & 80.7 & $73 \%$ & $89.9 \%$ \\
West & 9.6 & $10.7 \%$ & $7.2 \%$ \\
Pacific & 0.5 & $0.8 \%$ & $0 \%$ \\
\hline
\end{tabular}

According to US Census Regions 
Figure 1. Scree Plot of SEL Attitudes Scale Factor Analysis

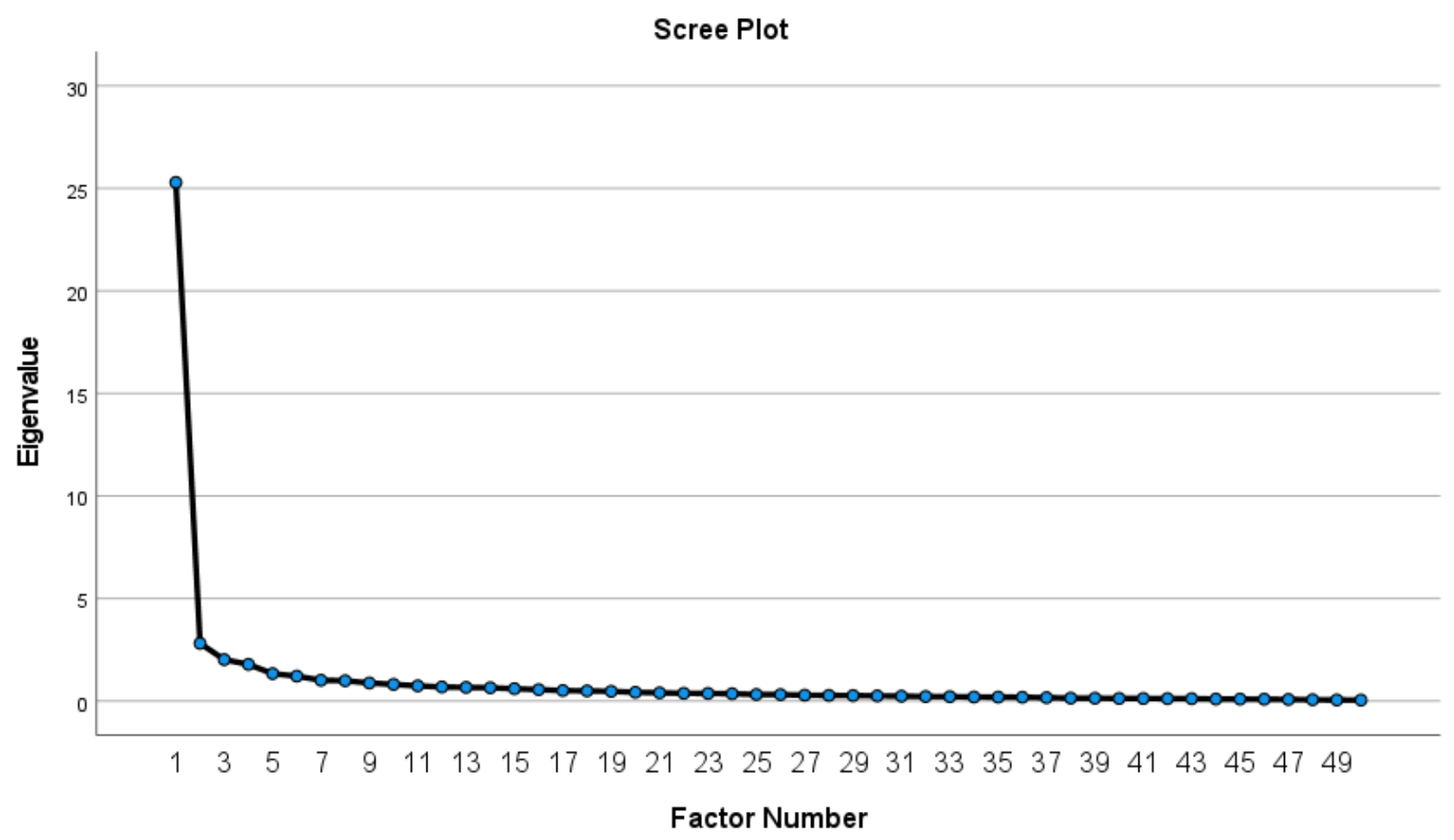


Table 3. Factor Matrix of SEL Attitudes Scale Factor Analysis

Item

Factor Loading

"Within the schools, students should be taught to..."

...effectively communicate their needs. $\quad .83$

...understand how feelings influence their behavior. $\quad .80$

....identify problems. $\quad .80$

...evaluate the effectiveness of their decisions. $\quad .80$

$\begin{array}{ll}\text {...successfully monitor one's own progress toward reaching a goal. } & .79\end{array}$

...recognize their own strengths. $\quad .78$

...establish positive relationships with others. $\quad .78$

$\begin{array}{ll}\text {...develop self-confidence. } & .78\end{array}$

$\begin{array}{ll}\text {...effectively express their emotions. } & .77\end{array}$

...understand how their thoughts influence their behavior. $\quad .77$

...understand how emotions make their bodies feel (e.g. tense when $\quad .76$ angry).

...effectively listen to others. $\quad .76$

...identify their own emotions. $\quad .76$

...manage their stress. $\quad .76$

...control their impulses. $\quad .75$

$\begin{array}{ll}\text {...regulate their own behaviors. } & .75\end{array}$

...generate possible solutions to problems. $\quad .75$

...show concern for the feelings of others. $\quad .75$

...understand others' emotions.

...identify their own thoughts.

...think about previous experiences with similar problems and how $\quad .74$

they impact decision-making.

...understand nonverbal communication such as tone of voice and $\quad .74$ body language.

...consider the wellbeing of others in decision-making. $\quad .73$

$\begin{array}{ll}\text {...regulate their feelings. } & .72 \\ \text {..maintain positive relationships. }\end{array}$

$\begin{array}{ll}\text {...maintain positive relationships. } & .71\end{array}$

...recognize social supports available to them, such as family, school, .71 and community.

...motivate themselves to reach their goals. $\quad .71$

$\begin{array}{ll}\text {...be kind toward others. } & .70\end{array}$

$\begin{array}{ll}\text {...initiate interactions with others. } & .70\end{array}$

$\begin{array}{ll}\text {...reciprocate during social interactions. } & .69\end{array}$

...develop self-efficacy, or believe they can be successful with tasks. $\quad .69$

...develop self-discipline in order to reach their goals.

...display empathy toward others. $\quad .68$

...consider the wellbeing of themselves in decision-making. $\quad .68$

....accept responsibility for their actions. $\quad .67$

...develop a sense of optimism about their future. $\quad .67$

...demonstrate respect for others. $\quad .67$ 
...set goals for themselves. $\quad .66$

...negotiate through conflicts. $\quad .63$

...take the perspective of others in various situations.

...ask for help when needed in making decisions.

....analyze problem situations. $\quad .62$

...recognize that their behaviors affect others. $\quad .61$

...identify their personal values and beliefs. $\quad .59$

....appreciate diversity among people. $\quad .59$

$\begin{array}{ll}\text {...regulate their thoughts. } & .58\end{array}$

...consider consequences of possible decisions. $\quad .57$

$\begin{array}{ll}\text {...cooperate with others. } & .57\end{array}$

...organize their materials. $\quad .55$

...understand social norms for behavior. $\quad .46$

Table 4. Factor Matrix of SEL Effectiveness Scale Factor Analysis

Item

Factor Loading

Social-emotional learning positively impacts academic achievement. $\quad .84$

Social-emotional learning is effective for students from all income $\quad 82$ levels.

Social-emotional learning is effective for students of all grades, $\quad .79$ kindergarten through twelfth grade.

Social-emotional learning is effective for students of all racial and $\quad .79$ ethnic identities.

Social-emotional learning is effective in helping children learn social skills. $\quad .75$

Social-emotional learning is effective for students with and without $\quad .75$ disabilities.

Social-emotional learning is effective in helping children learn about $\quad .72$ emotions.

Social-emotional learning positively impacts school climate. .61

Schools are natural sites of exposure to social-emotional learning, so it $\quad .59$ should be addressed in the schools.

Social-emotional learning is only effective for students who need it. $* \mathrm{R}$ .38

* factor excluded; $\mathrm{X}^{\mathrm{R}}$ reverse coded 
Table 5. Factor Matrix of Academic Priority Scale Factor Analysis

Item

Factor Loading

Overall, academics are more important than social-emotional learning. ${ }^{\mathrm{R}} \quad{ }^{\mathrm{R}} \quad .85$

Instruction in reading is more important than social-emotional learning. ${ }^{\mathrm{R}} \quad .80$

Instruction in math is more important than social-emotional learning. ${ }^{\mathrm{R}} \quad .77$

Social-emotional learning doesn't belong in the schools. ${ }^{\mathrm{R}} \quad .70$

Attention to social-emotional learning takes too much time away from $\quad .68$ academics. ${ }^{\mathrm{R}}$

The school's primary job is to teach academic subjects. ${ }^{\mathrm{R}} \quad .61$

Schools should support the whole student, including academics and social, $\quad .59$ emotional, and behavioral development.

Social-emotional learning should be given the same amount of instructional $\quad .55$ time as academics.

Academics must take priority over social-emotional learning for the sake of $\quad .50$ standardized testing. ${ }^{\mathrm{R}}$

Social-emotional learning should be addressed in other contexts and not within the school. ${ }^{\mathrm{R}}$

$\mathrm{X}^{\mathrm{R}}$ reverse coded 